\title{
Aesthetic in Designing Shoes; a Necessity to Meet the Needs of Customers
}

\author{
Parvin Shokri ${ }^{1}$ \\ ${ }^{1}$ Department of Industrial Design, Alzahra University, Tehran, Iran \\ Correspondence: Parvin Shokri, Assistant Professor, Department of Industrial Design, Alzahra University, \\ Tehran, Iran. Tel: 98-21-4420-2773. E-mail: pshokri@alzahra.ac.ir
}

Received: April 20, 2016

Accepted: November 7, 2016

Online Published: November 16, 2016

doi:10.5539/ass.v12n12p246

URL: http://dx.doi.org/10.5539/ass.v12n12p246

\begin{abstract}
Mind is at peace when concentrating on beauties. Beauty is the splendor of order and when things are as they should be, peace is manifesting in mind and spirit. Beauty and peace could easily be found in ordinary things when the principles were considered in their designing. By refining the design idea of a particular type of shoe, in this study the important role of design factors affecting aesthetics in designing process of products are revealed. Designing functional products beautifully may also lead to better and longer use of them and as a consequence save our environment by better management of natural resources.
\end{abstract}

Keywords: Aesthetics, Product Design, Shoe Design

\section{Introduction}

Among many factors that affect the development of a product, this study concentrates on aesthetic properties. Beauty is important and any attempt to make the appearance of the products beautiful is admirable since it has the power to attract one's mind and thought and causes his awareness to be completely centered on the present time. As relaxation at places close to nature is the serious need after facing a long exhausted time, the mind is at peace while concentrating on the beauty of the objects and this is the fact that makes the beautiful appearance of products so important.

Community, life-styles, culture, Family, and friends are among factors that aid in the influence of one's perception of what beauty is. These factors were classified in Bronfenbrenner's Ecological Model as the Micro and Macro systems (Bronfenbrenner, 1994).

Aesthetics can be a powerful design driver that helps connect dynamic forms to social and ethical aspects (Ross \& Wensveen, 2010). The appearance attributes of a product including modernity, simplicity and unity can influence the users' overall impression and satisfaction of the product. The whole process of deriving a meaning from a product appearance is summarized in two steps and is shown in Figure1 (Blijlevens et al., 2009).

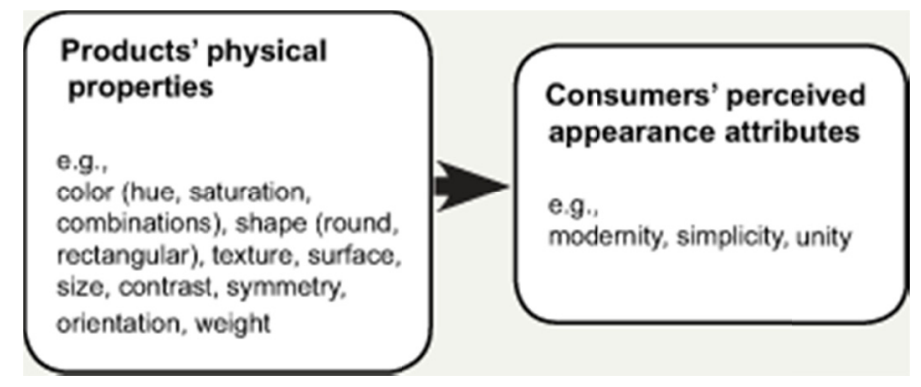

Figure 1. Two-step model of product appearance perception

In this study by refining the design of a particular type of shoe, the role of aesthetics and its principles in beautifying the appearance of a product becomes clearer.

Designing attractive as well as functional shoes may also lead to save our environment by the tendency of the users for caring more their beautiful shoes while using them. 


\section{Product Design}

Product design involves a broad approach to the designing and making of new innovative products. Product designers are also asked to develop an existing design, rather than to design a new product from scratch. Designing the right products at the right cost with strong marketing support will ensure the success. To stay competitive, it is necessary to keep the product fresh; which means keeping up with trends in the market, emerging technology and introducing new refinements to the existing products.

Product analysis is defined as the process of identifying, looking at or disassembling a product and classifying its main features. The aim is to understand more about a product for further improving it. Many factors influence the development of a product, some are listed in Figure 2.

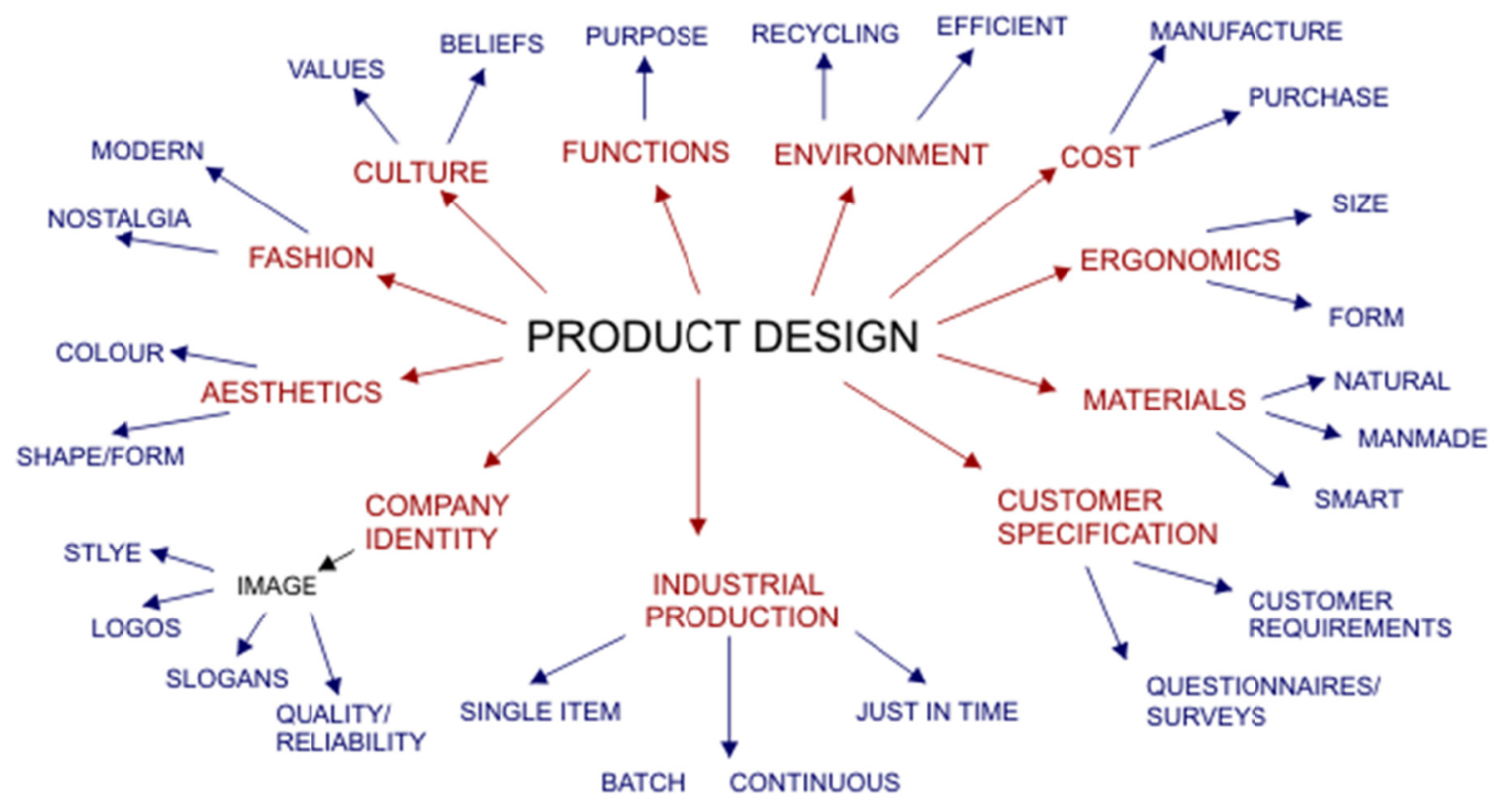

Figure 2. Factors influencing the development of a product (Ryan, 2009)

Match to customer needs is considered the strongest indicator of success in developing new products (Haverila, 2010). Considering customer needs leads to define a strong product requirements document which can satisfy successfully the purpose of a product. This effort is in many respects the most important phase of a product design as it sets the foundation for all subsequent phases of the product's life cycle. Even though many items including human factors requirements, performance of the products and their functional characteristics must be considered in order to compile a complete list of any product requirements; each product has its own specifications which should be considered carefully.

While practicality is the key when it comes to footwear choices, societal pressures of beauty have promoted consumers to look beyond function. Although shoes may be in fact the most important part of an individual's attire, as no other article of clothing must fit so precisely and perform critical mechanical functions such as transferring body weight; still it seems the focus of differentiation moves from function to aesthetics of forms and as the consequence shoes are often designed to look stylish.

\section{Aesthetics}

Aesthetics is a fundamental design factor and is studied in disciplines such as philosophy, art criticism, art history, psychology, anthropology, experimental aesthetics, industrial design and more recently consumer research. The main visual elements of design are point, line, color, texture, shape, and form. These elements are used to create the principles of compositional design including center of interest (emphasis), balance, proportion, harmony, contrast, unity, directional movement, variety, and rhythm. These principles of design are the recipe for a good work of art. Proper combination of the elements creates an aesthetic placement of things and produces a good design. 
According to the principles of good design by Deter Rams (Note 1), the aesthetic quality of a product is integral to its usefulness because products are used every day and have an effect on people and their well being and only well-executed objects can be beautiful.

Aesthetic quality of a product can also have a dramatic impact on its market differentiation. The importance of studying the aesthetic aspect of interaction between human and products was confirmed by an experiment which was conducted to test the relationships between users' perceptions of a computerized system's beauty and usability. In this experiment perceptions were elicited before and after the participants used an Automated Teller Machine (ATM). The results revealed that the degree of system's aesthetics affected the post-use perceptions of both aesthetics and usability, whereas the degree of actual usability had no such effect (Tractinsky et al., 2000).

Identification addresses the human need to express one's self through objects. Hedonic attributes according to Hassenzahl's model describes how important it is for users to express themselves through the objects around them and how much energy they focus on selecting objects to promote their personal brand (Hassenzahl, 2002). Individuality is also conceptualized by Reckwitz (Reckwitz, 2002) and according to this study although the styles and meanings of specific products may be routine and socially learned; still each individual creates a unique style through her or his own particular combination of fashion practices.

Visual aesthetics refers to the beauty or the pleasing appearance of things. The aesthetic response to an artifact is usually the first response and the appearance of a product may serve as a signal for unobservable attributes of quality, much as a brand does for products and services (Ulrich, 2013). Evidently shape, color, form and texture that please the aesthetic senses especially sight are the main characteristics of a product like a pair of shoes which represent its beauty.

\section{Shoe Design}

Shoe design is based primarily on the anatomy and the mechanical functionality of the human foot. The second consideration in designing shoes is the intended use of the footwear which determines the choice of material and structure of the shoes. Finally, style and fashion which are concerned in this study influence the outward appearance of the shoe without compromising its comfort.

The style applied to the outside of a product can quite easily influence the technology inside it and by other means aesthetics can alter the production or manufacturing techniques through which a pair of shoes is made.

Lines as the basic elements of design play an important role in designing shoes and as a consequence their manufacturing process. In designing shoes, lines as shown in Figure 3 are the boundaries of various parts and sometimes represent stitches for attaching two parts with thread.

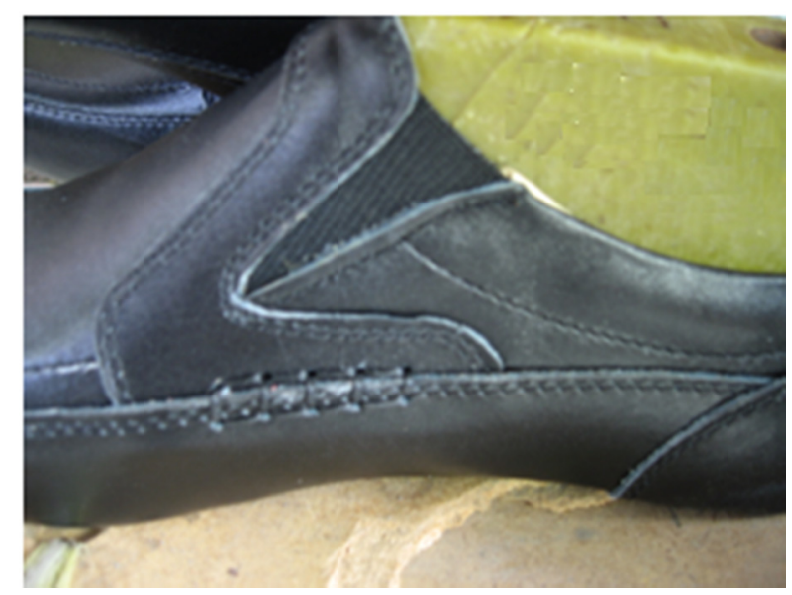

Figure 3. The role of lines in designing shoes

A particular style of shoe and its outlines (Model A) in front view is shown in Figure 4. The sign in Model A is showing the center of interest (or point of focus) where it immediately attracts attention. Though this emphasis is a kind of interruption in the fundamental pattern or movement of the viewer's eye through the composition; however parallel lines running horizontally in this model still make human eye to run left and right aimlessly. It seems some sort of line is needed to help human eye recognize, for instance, on which side the shape is supposed to end. With just a few detectable changes of lines and keeping the same color and material, Model B seems 
more pleasing in which its shape variation is easily recognizable. It should be emphasized that in this practice all efforts were concerned on giving a more beautiful appearance to the product with minimum change in order to show the power of simple principles of design.
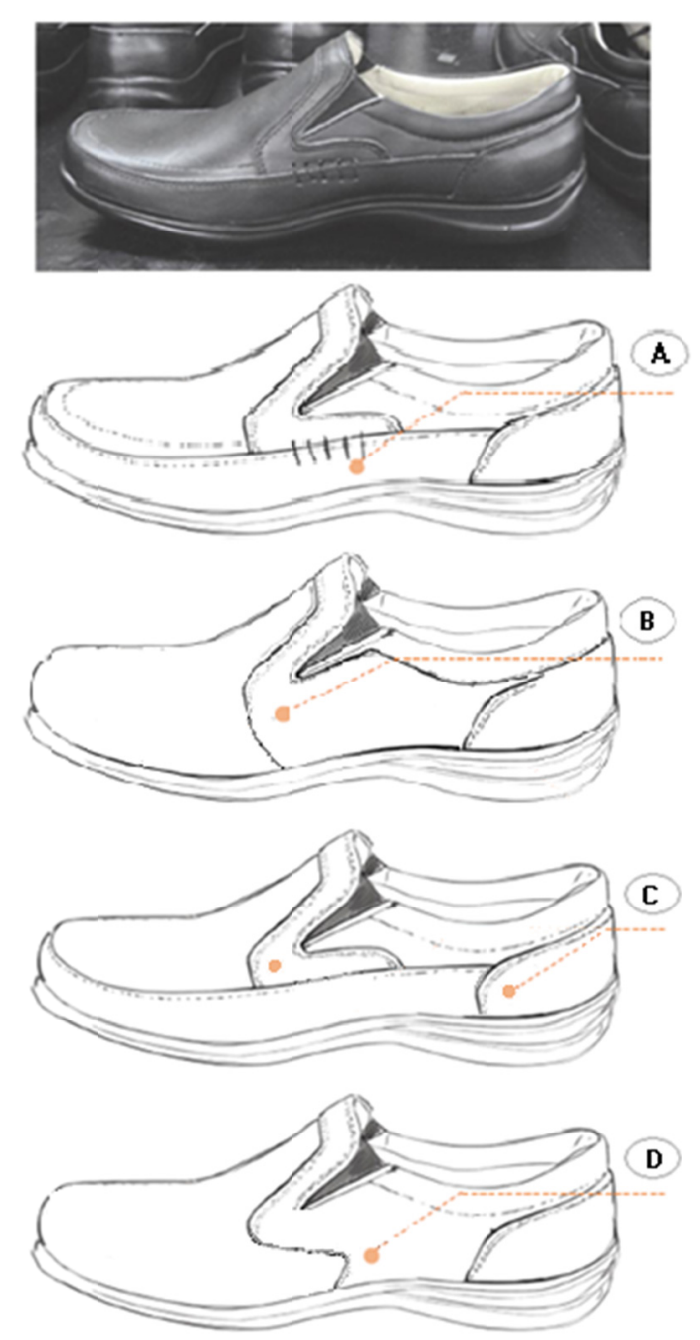

Figure 4. Redesigning a particular type of shoe

Eliminating some of the lines reduces the number of parts and as a consequence simplifies its manufacturing process. As can be seen beautifying the appearance of a product does not always mean to increase its price; at times it just aligns with more simplicity.

In Figure 4 the other variations of Model $\mathrm{A}$ can also be seen. Model $\mathrm{C}$ is a modified version with even less change in the original design idea comparing with Model B. In Model $\mathrm{C}$ the signs are showing small parallel lines which increase the design's harmony (Note 2).

Using an S-shaped curved line in Model D makes the design even more pleasant. S-shaped curved lines signify liveliness and activity and excite the attention of the viewer according to the Hogarth's theory of aesthetics as described in his Analysis of Beauty (Hogarth, 2010).

A high appreciation of a product on the part of the user is an important prerequisite for long use. Aesthetics satisfies essential human desires and accomplish psychological needs. It is a source of joy and influence attitudes and decision making. Thus, beauty can be thought of as "just another attribute" in a user's evaluation of preference, along with durability and cost. Aesthetic design implies that the designer or the organization respects their audience, is sensitive to people's needs and desires and puts thought and effort into the design of a product and the environment.

Shoes which were designed carefully will rather be cared and repaired than exchanged for new ones. This 
tendency of users is align with the results of Pan et al. (Pan et al., 2015) in resolving their hypothesis that fashion might be re-conceptualized as a force for sustainability, rather than un-sustainability if only fashion-oriented design aligns with innovation to push forward social progress (Walker, 2006) rather than premature obsolescence of resources at the expense of mode for decreasing the mass production cost. According to the study of Pan et al. (Pan et al., 2015), the extent to which objects can come to resonate with ones' values and personal identity may be a cause that inspires one to invest in long-term care and maintenance of possessions, rather than always rushing out to buy the latest style.

\section{Conclusions}

- Principles of aesthetics introduce valuable guidelines to designers for fulfilling consumer preferences in their design.

- Improving the appearance of a product does not always mean increasing its price.

- Aesthetic design of shoes may lead to long use of them and consequently, minimize consumption of resources.

\section{References}

Blijlevens, J., Creusen, M.E.H., \& Schoormans, J.P.L. (2009). How consumers perceive product appearance: The identification of three product appearance attributes. International Journal of Design, 3(3), 27-35.

Bronfenbrenner, U. (1994). Ecological models of human development. International Encyclopedia of Education, 3.Oxford: Elsevier.

Hassenzahl, M. (2002). The effect of perceived hedonic quality on product appealingness. International Journal of Human-Computer Interaction, 13(4), 481-499. http://dx. doi.org/10.1207/S15327590IJHC1304_07

Haverila, M. (2010). Factors affecting new product success in technology companies: the case of Finland. $\begin{array}{llll}\text { International Journal of Product Development, } & 12(2), & 176-198 .\end{array}$ http://dx.doi.org/10.1504/IJPD.2010.034995

Hogarth, W. (2010). The analysis of beauty; Written with a view of fixing the fluctuating ideas of taste. Printed by J. Reeves, London.

Pan, Y., Roedl, D., Blevis, E., \&Thomas, J.C. (2015). Fashion thinking: Fashion practices and sustainable interaction design. International Journal of Design, 9(1), 53-66.

Reckwitz, A. (2002). Toward a theory of social practices: A development in culturalist theorizing. European Journal of Social Theory, 5(2), 243-263. http://dx.doi.org/10.1177/13684310222225432

Ross, P.R., \& Wensveen, S.A.G. (2010). Designing aesthetics of behavior in interaction: Using aesthetic experience as a mechanism for design. International Journal of Design, 4(2), 3-13.

Ryan, V. (2009). Factors that influence product development, World Association of Technology Teachers, Retrieved from http://www.technologystudent.com

Tractinsky, N., Katz, A.S., \& Ikar, D. (2000). What is beautiful is usable. Interacting With Computers, 13(2), 127-145. http://dx.doi.org/10.1016/S0953-5438(00)00031-X

Ulrich, K.T. (2013). Design: Creation of artifacts in society. University of Pennsylvania, USA.

Walker, S. (2006). Sustainable by design: Explorations in theory and practice. Sterling, VA: Earthscan.

\section{Notes}

Note 1. Deter Rams is a German industrial designer who was a chief design officer at Braun (1961- 1995).

Note 2. Harmony in visual design can be achieved through repetition and rhythm. Repetition reemphasizes visual units, connects parts and creates an area of attention.

\section{Copyrights}

Copyright for this article is retained by the author(s), with first publication rights granted to the journal.

This is an open-access article distributed under the terms and conditions of the Creative Commons Attribution license (http://creativecommons.org/licenses/by/4.0/). 